This is a pre-press version of

Roberts, B., 2013. Memories of Inauthenticity: Stiegler and the lost spirit of capitalism. In G. Moore and C. Howells, eds. Stiegler and Technics. Edinburgh: Edinburgh University Press, pp. 225-239.

\title{
Memories of inauthenticity: Stiegler and the lost spirit of capitalism
}

The aim of this essay is to discuss Bernard Stiegler's arguments about the condition and fate of contemporary capitalism. These arguments are formulated most succintly in For a New Critique of Political Economy but elements of this 'new critique' are discussed at greater length throughout Stiegler's recent work and in particular in the series Mécréance et Discrédit (Disbelief and Discredit and De la Misère Symbolique (On Symbolic Misery). In the following discussion I have chosen to focus primarily on the third volume of the former, entitled L'Esprit perdu du capitalisme (The Lost Spirit of Capitalism), the first part of which is dedicated to a detailed critique of the Luc Boltanski and Ève Chiapello's The New Spirit of Capitalism. There are two reasons for this focus. The first is that Boltanski and Chiapellos's book has become an extremely influential account of contemporary capitalism; Stiegler's arguments here help to demonstrate the problems and limitations of its approach. The second is that the contrast with Boltanski and Chiapello helps to bring out much that is genuinely novel and interesting about Stiegler's own account of capitalism. It demonstrates in some detail the way in which his transformation of work by Derrida, Simondon and others has allowed a rearticulation of some of the concerns of the Frankfurt School. It also shows how in his later work Freudian concepts have extended his diagnosis of 'disindividuation' in contemporary capitalism.

Boltanski and Chiapello distinguish the 'social critique' of capitalism, embodied in a demand for equality, from its 'artist critique' which they associate with a demand for liberation and authenticity. They go on to argue, based on a comparison of 1960s and 1990s French management literature, that contemporary capitalism can be understood partly as a response to the artistic critique, which it attempts to assimilate and incorporate. In this essay I will discuss Bernard Stiegler's criticisms of their work, including his objection that we need to understand current developments not in terms of a new but a 'lost' spirit of capitalism. I will go on to consider what the implications of this debate are for his wider project and in particular its critique of 'hyperindustrial' capitalism.

\section{The new spirit of capitalism}

To prepare the ground for this discussion we need to recap briefly the aims of The New Spirit of Capitalism. Boltanski and Chiapello in fact distance themselves from the project that the title would seem to suggest they are undertaking, that is, a contemporary reworking of Weber. They put to one side the wider question of the ethos of capitalism, preferring to define spirit more narrowly as 'expressed in a certainty imparted to cadres about the "right" actions to be performed to make a profit, and the legitimacy of these actions' (Boltanski \& Chiapello 2007: 16). As they put it:

We shall set aside the predispositions towards the world required to participate in capitalism as a cosmos - means-end compatibility, practical rationality, aptitude for calculation, autonomisation of economic activities, an instrumental relation to nature, and so on - as well as the more general justifications of capitalism produced in the main by economic science ... Our intention is to study observed variations, not to offer an exhaustive description of all the constituents of the spirit of capitalism. This will lead us to detach the category of spirit of capitalism from the substantial content, in terms of ethos, which it is bound up with in Weber... (Boltanski \& Chiapello 2007: 11 [original emphasis]) 
The key point here is the focus on 'observed variations' which prepares the ground for the sociological empirical work on which the book's claims rest. The wider question of 'ethos' is therefore not addressed by The New Spirit of Capitalism. If the concept of spirit here is narrower than in Weber, it is perhaps partly in order to justify the focus on different eras of management discourse. Boltanski and Chiapello's spirit of capitalism provides those engaged in managing capitalism (but not its main beneficiaries) with an enthusiasm for their endeavour, a minimum of security and some sense that their activity is compatible with the common good (2007: 16). The focus on comparison and variation also indicates that this is not so much a thesis about capitalism in general as about changes within capitalism and particularly those changes in capitalist spirit that the authors identify between the 1960s and the present day.

Indeed Boltanski and Chiapello identify three distinct spirits of capitalism: the first, which has its roots in the nineteenth century and can be seen in the figure of the bourgeois entrepreneur and the family business, stresses 'gambling, speculation, risk, innovation' (2007: 17). The second, which develops between the 1930s and 1960s, is the spirit of the bureaucratic, centralised large corporation and emphasises economies of scale, production standardisation [and] the rational organisation of work' (2007: 18). The third and eponymous 'new spirit' of capitalism has emerged between the 1960s and the present day and consists in a highly decentralised networked form of capitalism, characterised by 'flatter' organisational hierarchy, much greater autonomy within firms for both individuals and teams, lower job security and the proliferation of temporary contracts and outsourcing.

Each spirit of capitalism also incorporates a justification of capitalism (2007: 20) and the changes between different spirits can therefore be understood as shifts in the nature of this justification in response to the various criticisms that are made of it. The evolution of the spirit of capitalism is therefore intimately bound up with the criticisms that are made of the capitalist mode of accumulation. Chiapello categorises these as follows:

Capitalism is criticised: (a) as a source of disenchantment and of inauthentic goods, persons, and lifestyles; (b) as a source of oppression that is opposed to freedom, autonomy, and creativity; (c) as a source of misery and inequality; and (d) as a source of egotism entailing the destruction of forms of solidarity. (Chiapello 2004: 586)

For Boltanski and Chiapello - and this is where their analysis itself moves into 'authentically' new terrain -- the first two criticisms belong to something which they propose to call artist or artistic ${ }^{1}$ critique of capitalism, the latter two belong to its 'social critique'. In other words, artist critique is generally characterised by demands for autonomy and authenticity, whereas social critique opposes inequality and egotism. These two critiques, though sometimes exemplarily combined - as for Chiapello is the case with the Frankfurt School (2004: 586n5) - are not straightforwardly compatible and may even conflict, typically being articulated by distinctively different social groups. The rather more substantial claim here is that the 'new spirit' of capitalism, as evinced by their comparison of management literature from the 1960s and 1990s, is partly a response to the artist critique that they identify, particularly as embodied in the movement culminating in May $1968 .^{2}$ That is to say that 1990 s-style 'neo-management aims to respond to demands for authenticity and freedom, which have historically been articulated in interrelated fashion by what we have called the "artistic critique" (2007: 97). This response to artist critique consists not only in less bureaucratic, 'more human', forms of organisation but also the invention and marketing of products which are 'attuned to demand, personalised, and which satisfy "genuine needs"' (2007: 99).

Stiegler's longest sustained account of Boltanski and Chiapello is in L'Esprit perdu $d u$ capitalisme (The Lost Spirit of Capitalism), the third volume of his series Mécréance et Discrédit (Disbelief and Discredit). As the title suggests, while endorsing some aspects of their work, Stiegler sharply disagrees with their diagnosis concerning the 'spirit' of contemporary capitalism. The current situation is one in which capitalism is in crisis and that crisis is characterised by a loss of spirit: 
Although I often agree with these analyses, I don't, for all that, believe that there is nowadays a 'new' spirit of capitalism, whatever that may be - nor that this would be its third stage. On the contrary I believe that what is at stake and in question here is the libidinal economy of capitalism, in as much as it leads to the liquidation of all the sublimations that constitute the superego, which is always supported by processes of sublimation, the fruits of which we call 'spiritual works'. (DD3, 18 [original emphasis])

As can be seen in this quote, Stiegler's understanding of 'spirit' is rather different from the carefully constrained sense in which, as we have seen, Boltanski and Chiapello use it. In one way he stays closer to Weber, seeing in contemporary developments a generalisation of the 'disenchantment' that was described in the latter's The Protestant Ethic and the Spirit of Capitalism (Weber 1958; DD3, 19). However, Stiegler also redefines this loss of spirit here in Freudian terms, as desublimation and as destruction of the libidinal economy on which capitalism depends. Allied to this Freudian analysis is an understanding of spirit as psychic and collective individuation, a term drawn from the work of Gilbert Simondon (2007). In effect the analysis of 'loss of spirit' is a blend of desublimation and disindividuation. As Stiegler puts it, 'the process of psychic and collective individuation - in which the simultaneously conjunctive and disjunctive and is, I believe,constitutive of spirit itself [. . .] -- presupposes sublimation' (DD3, 29). Stiegler's argument here about loss of spirit therefore recalls earlier arguments about the loss of individuation drawn from his reading of Simondon.

In Du Mode d'existence des objets techniques (On the Mode of Existence of Technical Objects) (1958), Simondon argues that the rise of the machine tool removes the ability of the skilled worker to differentiate their labour from that of other workers: a 'loss of individuation' which for Stiegler is extended at the level of consciousness by the new teletechnologies and their industrialisation of memory. As he puts it in the first volume of De la Misère symbolique (Symbolic Misery), 'the current loss of individuation is a stage of grammatisation in which three individuations, psychic, collective and techno-machinic, generalise formalisation through calculation' (SM1, 142). ${ }^{1}$ Here Stiegler adds to Simondon's analysis the idea that the process of industrialisation is also a grammatisation, that is to say, a process, analogous to that of the development of writing, by which idiomatic actions (for example, those of the weaver) are standardised, discretised and materialised (for example, in the Jacquard loom) (CPE, 10-11):

industrial machines allow the actions of manufacture to be discretised, formalised and reproduced, duplicating the know-how of the worker and putting it into the machine. Industrial machinery reproduces the actions of labour in the same way that writing permits the reproduction of speech and printing allows the reproduction of copies. It also permits the rationalisation of actions, just as writing allows the rationalisation of a particular way of writing - and therefore of speaking, of thinking - in what will become a homogeneous linguistic milieu. (EHP, 57)

This stress on industrialisation as grammatisation is an important distinguishing feature in Stiegler's account of contemporary capitalism. He does not accept the thesis that modern societies are 'post-industrial'. Rather he regards them as hyperindustrial, as the continuation of modernity towards 'the industrialisation of everything' (DD1, 102-3; SM1, 98). The hyperindustrial marks the extension of industrialisation from the mechanical to the computational, from the manufacture of goods to the industrialisation of memory and culture, and a corresponding expansion of proletarianisation from the producer to the consumer, from the working to the middle class (DD1, 62). This is because grammatisation is at the heart of the way in which capitalism is to be understood, that is, capitalism is itself a specific epoch in the Western process of grammatisation:

Beyond that 'rationalisation' described by Weber, and the separation of capital and labour

1 'La perte d'individuation actuelle est un stade de la grammatisation òu les trois individuations psychique, collective et techno-machinique généralisent la formalisation par le calcul' 
described by Marx, capitalism is the expression of a tendency towards the mechanical externalisation of that which characterises the singularities composing the process of individuation; and, as such, it is the mechanised epoch of what in De la Misère symbolique 1, I have called grammatisation. Nevertheless this tendency, as mechanical exteriorisation, has the effect of producing a standardisation and a formalisation, submitting everything that it formalises to calculability. (DD1, 38)

What is unique about contemporary capitalism in its current epoch, then, is that this tendency toward exteriorisation has become hegemonic (37), resulting in the hypersynchronisation of 'singularities' and the loss of individuation or disindividuation which we have just discussed. Unless singularities can be 'recast [rejouer] on a new plane', this tendency can lead to disaster; in other words, we need to avoid the risk that 'capitalism could brutally and prematurely come to a very bad end, and us with it, though the decomposition of its tendencies' (DD1, 38; DD3, 27); Stiegler's concern here is to save capitalism from itself.

There are a number of obvious differences here with the analysis provided by Boltanski and Chiapello. The standardisation that they associate particularly with the 'second spirit' of capitalism (roughly 1930s - 1960s), for Stiegler forms part of an essential tendency towards mechanical exteriorisation and is pushed even further in today's creative or cognitive capitalism. For Boltanski and Chiapello (writing in 1999, so before the global financial crises of 2007-8), capitalism is 'flourishing' (2007: xxxvi); for Stiegler it is on the verge of self-destruction (DD3, 26-27). What they see as 'ideological changes' within capitalism, he sees as different expressions of a continuous tendency (to exteriorisation). Indeed beyond the grammatisation thesis, Stiegler's understanding of the limits of capitalism are classically 'tendentialist': a tendency for the rate of profit to fall, a tendency for the libidinal energy of consumption to become exhausted, a tendency to exceed the natural resources of the planet (CPE, 23-25, 92). ${ }^{3}$ In other words, he sees capitalism as transformed through its own inherent dynamics, through reaching its tendential limits.

On the other hand, the authors of The New Spirit of Capitalism depict the spirit of capitalism as evolving in response to the critiques made of it, as a result of the 'three-sided game' between critique, capitalism and its legitimising spirit (2007: 29-30). The emphasis here is on the sociology of management cadres and very short shrift is given to economic science as a means of understanding capitalist spirit. Boltanski and Chiapello are equally dismissive of the idea that changes can be understood in technological terms, seeing here the risk of 'technological determinism' (2007: xix). Therefore, despite their emphasis on the centrality of the network form to the new spirit of capitalism, there is very little discussion of information networks. As Stiegler argues:

What is very much neglected in the analysis of Luc Boltanski and Eve Chiapello, in other words, is not only the place of the media, but also that of technics, which is presented here only as a connexionist model, the implications of which need to be verified anyway (why connexion rather than rhizome, for example?) What they frequently evoke as personalisation and one-to-one, 'or point to point'contact, is a result ofnetwork connectivity and technical evolution long before being the response to so-called 'demand' [...]. The role of information and its technologies is not analysed at all. (DD3, 53-4)

The argument here is that the 'connexionist' model is not simply, as Boltanski and Chiapello argue, a change brought about by artist critique of captitalism's conformity, formulated as a demand for 'personalisation'. Rather it is underpinned by a technical and informational evolution that begins long before the changes in management practice associated with the 'new spirit'. To assert, as Stiegler does here, the importance of these technological supports is not necessarily to argue for a form of technological determinism, or the assumption that technological change drives social change in a deterministic fashion. As I have argued elsewhere, Stiegler's ideas around technics and grammatisation do not in fact privilege technology as the determining factor in social relations 
(Roberts 2012, forthcoming). This is partly because he sees technics, as the exteriorisation of memory, as itself a form of contingency, that is, an escape from the biological programme. But it is also because from the beginning of his work Stiegler describes the prosthetic relationship between the human and technics as a structure without origin, where neither side plays the role of 'cause' to the other as 'effect' (this is analogous to the way Derrida sees language as difference, as a structure without origin). In such a structure to talk of a determining relationship, such as technological determinism, makes no sense. This is why Stiegler talks of the 'differance of the human' in the first volume of Technics and Time, for example (TT1, 134-145). But he also makes this argument in relation to the centrality of spirit in Boltanski and Chiapello's account:

It is not ideas which cause phenomena. That doesn't mean to say that it is something else which causes ideas. It doesn't signify, for example, that technical individuation or even transformation of the relations of production would be the cause of the 'superstructural' creation of ideas. (DD3, 49)

In other words, to suggest that capitalism's new networked spirit cannot be thought separately from the materiality of information networks themselves is not an argument that changes in technology can simply explain the transformation of spirit. Rather it is to see the two in a relationship of 'co-individuation' within a single process:

Are networks the origins of organisations and ideas, or the inverse? False problems. Nothing is the origin of anything else: all these - individuals, ideas, organisations, technics are formed in a process. (DD3, 50, [original emphasis])

The problem for Stiegler, then, with Boltanski and Chiapello's emphasis on the role of spirit is that it leaves in place a virtually uninterrogated dualism of materialism/idealism or base/superstructure (49-50). But it is just this opposition between base and superstructure that the thinking of technics, and in particular mnemotechnics, the technical preservation of memory, refuses. As Stiegler puts it, 'retentional supports, infrastructure, constitute retentional apparatus, superstructure' (DD3, 57). As a result, the opposition between infrastructure and superstructure is 'inoperative' (DD3, 57).

\section{Consumption and the role of authenticity}

Another facet of the narrow way in which Boltanski and Chiapello define 'spirit', or the separation of spirit from ethos which we discussed above, is that their focus on management cadres is also a focus on production and a relative neglect of the role of consumption. This leads to an emphasis on the management rather than creation of consumer demand. Indeed at times it can seem as if demand is almost naturalised within the account. Stiegler remarks on this tendency in the following passage from the discussion of 1990s management discourse in The New Spirit of Capitalism:

new-style management does indeed offer various responses to the critique of disenchantment by promoting the creation of products that are attuned to demand, personalised and which satisfy 'genuine needs', as well as more personal, more human forms of organisation. (Boltanski \& Chiapello 2007: 99)

But, as Stiegler, puts it, 'is there really a demand?' (DD3, 38) And what is meant here by 'genuine need', even when surrounded by quotation marks? For Stiegler, such a social demand is always created and managed by capitalism, 'only an artifice in the service of generalised proletarianisation' (39). The apparently more 'personalised' response to this demand simply disguises more addictive forms of consumption. Indeed personalisation is but one more step in 'calculability applied to the control and reduction of singularities, here reduced to particularities' (DD3, 39). (This emphasises 
again the continuity between the industrial and 'hyperindustrial'.)

The relatively limited role played by consumption in The New Spirit of Capitalism's account is linked to a neglect of the role of desire in capitalism. Stiegler notes that the term is only really discussed in relation to Marx near the end of the book, where the idea that capitalism must create consumer desire is ascribed to artist critique (2007: 427). Boltanski and Chiapello therefore mostly ignore the ways in which capitalism does not merely respond to desire indirectly through the action of critique but is itself constituted through the creation, management and channelling of desire.

Stiegler's arguments here could be seen as evidence that what his analysis offers is a form of what, as we have seen, Boltanski and Chiapello call 'artist' critique. His revival of psychoanalytic concepts to describe capitalism's 'loss of spirit' and reworking of Marcuse in the second part of L'Esprit perdu du capitalisme seem to underline his affinity with the thinkers Boltanski and Chiapello associate with the 'artist critique' of 1968. It is no accident that Stiegler's readers have often made the comparison between his work and that of the Frankfurt school (Sinnerbrink 2009; Roberts 2006). Indeed superficially his diagnosis of a 'loss of individuation' in 'hyperindustrial' societies seems easily assimilated to what Boltanski and Chiapello label, in a problematically loose fashion, 'the critique of inauthenticity'.

As we have seen the critique of inauthenticity is at the heart of what Boltanski and Chiapello think of as 'artist critique'. But it's not always clear what they mean by this term. As Stiegler puts it:

One asks oneself if the word comes from Heidegger, from situationism, from Marcuse or elsewhere. None of these sources truly refer to this term, not even Adorno: it is rather the journalistic and leftist vulgate who use this very poor jargon. (DD3, 39)

As this suggests, The New Spirit of Capitalism is quick to include a wide range of philosophical positions under the umbrella of the 'critique of inauthenticity'. This becomes obvious in a passage near the end of the book where it is argued that even though Adorno explicitly rejects the concept of authenticity in Heidegger, the Dialectic of Enlightenment is 'perfectly compatible with the Heideggerian thematic of inauthenticity' (Boltanski and Chiapello 2007: 440-441; see also Adorno 1973, 1979). For these purposes it appears as if the critique of 'standardisation', 'massification', 'consensual levelling', 'conformist domination' are all equivalent (and indeed subsumed under) the 'critique of inauthenticity' (2007: 441). As Stiegler points out, this is apparent in a passage which describes how the commodification of the authentic, 'presupposes sources of authenticity [...] such as human beings, scenery, cafés where people feel comfortable, tastes, rhythms, ways of being and doing, and so on, which have not yet been introduced into the sphere of commodity circulation' (2007: 444). Here it appears that authenticity means little more than those aspects of human existence which have not yet been commodified. Yet this is a long way from the very technical sense in which Heidegger uses the word (1962: H42-3 / 68). Perhaps this is partly a translation issue between French and German: as Stiegler points out authenticity (authenticité) is a not unproblematic rendering of Heidegger's Eigentlichkeit and the sort of thing that Boltanski and Chiapello are describing might be closer to the German Echteit or Authentizität (DD3, 40). ${ }^{4}$

This sweeping interpretation of authenticity becomes even more problematic when it comes to the intellectual trends which The New Spirit of Capitalism argues are preventing a contemporary revival of artist critique. In a short but puzzling section entitled 'The discrediting of the quest for authenticity' (2007: 453-455), its authors argue that since the 1960s authenticity has been subject to a 'systematic labour of deconstruction' (2007: 453). The outcome of this deconstruction has apparently been to undermine the critique of the inauthenticity of capitalism. The principle thinkers responsible for this deconstruction (and who seem to be denounced here) are Bourdieu, Derrida and Deleuze. Let us leave to one side the rather strange coupling of these three thinkers, and the loose use of the term 'deconstruction' as a uniform description of their work. But to take just one example, that of Derrida, Boltanski and Chiapello's argument here seems quite tendentious. It is a bit of a stretch to argue that Derrida's deconstruction of speech and writing 'dismantles a figure that 
has, since Rousseau, constituted one of the most fertile springs for sustaining a demand for authenticity' (Boltanski and Chiapello 2007: 454). Perhaps realising here a need to 'show their working' the authors carry on this argument in a footnote. In response to Derrida's reading of Rousseau in Of Grammatology (they describe it as a 'long commentary'; it certainly is longer, and much more careful, than their own one-paragraph summary of Derrida), they argue:

In Rousseau, we doubtless find the first systematic expression of the requirement of authenticity in its modern form. The voice, as authentic presence and absolute proximity of the self to itself (and hence as truth), is opposed to writing as distance, mediation, loss of presence, and paving the way for illusion, just as the immediacy of the popular festival is contrasted with the artificiality of the theatrical spectacle, and, in another respect, with the way that direct democracy through the assembly of citizens is opposed to representative democracy, in which the general will [. . . ] risks being diverted and degraded into particular interests. (2007: 480n89, translation modified)

The net of authenticity is now being cast even wider. Even the philosophical privilege of speech over writing turns out to be foundational to the critique of capitalist inauthenticity and needs to defended from Derrida's reckless dismantling. But if Boltanski and Chiapello really want to establish the centrality of what Derrida calls phonocentrism to the thinking of authenticity they need to do so much more carefully than this. Similarly, given that the concept of authenticity is central to artist critique and given the assertion here that Rousseau is its foundational modern thinker, it is somewhat surprising that they do not dedicate some longer discussion to his work in the main text and relegate it instead to a footnote. Part of the problem here is that The New Spirit of Capitalism seems to move, without indicating as much, from a sociological and descriptive account of authenticity as a historical element in the critique of capitalism's second spirit to an analytic concept that turns out to be the foundation of critique in general. But this makes it even less plausible that they dedicate so little space to discussion of writers and thinkers whom they regard as crucial to the foundation and 'dismantling' of artist critique. A book that has been described approvingly as a 'dizzying theoretical tour of the past thirty years' is perhaps sometimes too dizzying (Budgen 2000: 150). As Stiegler points out, just four pages (in the French edition) are dedicated to the discussion of Derrida, Deleuze and Bourdieu, in comparison to 'hundreds and hundreds' devoted to the analysis of management texts (DD3, 44). Moreover, given their general treatment of singularity and authenticity as synonymous, it is odd that they do not discuss the theme of singularity in Derrida's work, nor that of idiomaticity, which is 'at the heart of the question of writing, the trace, difference, and so on, precisely as the question of singularity which exceeds that of singularity' (DD3, 44-5).

\section{Capitalism and its critique}

One of the strange aspects of Boltanski and Chiapello's 'three-sided game' between capitalism, its critique and the 'spirit of capitalism', is that they focus almost exclusively on the interaction between the latter poles and have much less to say about capitalism itself. At the outset of the thesis it is given a 'minimalist' definition as the 'imperative to unlimited accumulation of capital by formally peaceful means' (2007: 4). In general this definition seems to encompass a Marxist understanding of the division between capital and labour (2007: 6-7). But almost immediately the emphasis shifts to the question of how this 'absurd system' is legitimised through its spirit. It then becomes a question of the success or otherwise of critique in challenging and changing this spirit. Capitalism as an economic system is largely marginalised in this account. It is dealt a (presumably, winning) hand in their 'three-sided game' but its actual role in the interplay is rather mysterious. Everything happens as if the real game is 'spirit-critique' rather than 'capitalism-spirit-critique'. Indeed it looks as if this is not so much a three-sided game as a dialectic. In one sense this is perhaps an understandable feature of The New Spirit of Capitalism's 
sociological account. Presumably the fear is that too close a focus on economics leads to a neglect of the social and moral aspects of capitalism with which the book is concerned. Economic science is then dismissed as just one aspect of capitalism's legitimating spirit (and not even one that we should worry about too much) (2007: 12-14). But the problematic outcome of this is that capitalism as a system seems deprived of any proper history or dynamic, other than that of interminable accumulation. It is as if capitalism itself were a sort of constant force modulated through the changing ways in which it is legitimised. So factors that one might think belonged to the history of the capitalist system, such as the evolution of technology, changes in productivity, the rise of information networks, financialisation and so on, are sidelined by Boltanski and Chiapello's analysis.

Boltanski and Chiapello construct a convincing account of 1968 as a crisis in the legitimising spirit of capitalism, but the battle between spirit and critique can't be the source of every crisis in capitalism. (It seems doubtful that the financial crisis of 2007-8 was the result of brokers, traders, quantitative analysts and risk managers at firms like Lehman Brothers spending too much time reading anti-capitalist blogs.) What is excluded in Boltanski and Chiapello's account of the changing face of capitalism is the hypothesis that the spirit of capitalism might also respond to crises in capitalism itself, and not just as the result of artist and social critique. Suggesting that capitalism as a mode of accumulation might have its own dynamic and history, including its relationship with technical exteriorisation, doesn't necessarily mean either endorsing technological determinism or setting up economics as the final determining instance. It is precisely here that Stiegler's more nuanced account of the relationship between technics and culture comes to the fore - because it allows us to see the importance of the material specificity of technologies without simply opposing this dynamic to the human or contingency in general.

What is interesting is that, despite having highly divergent diagnoses concerning contemporary capitalism, both the authors of The New Spirit of Capitalism and Stiegler agree on one very important point, which is the need to renew critique. Indeed in a chapter entitled 'The Test of the Artistic Critique', Boltanski and Chiapello argue that artist critique itself needs to recover both from the unfortunate outcomes of its own success (that is, the incorporation of aspects of the critique, such as worker autonomy, in the 'new spirit' of capitalism) and, of course, as we have seen, from the 'disturbing effects' of the 'discrediting' of authenticity by Derrida and others.(2007: 419-482). However, their ideas on how this might be realised (beyond some legal codification of worker autonomy) seem to be mainly constrained to resisting commodification of new spheres of human activity (2007: 470-472). On the face of it this does not seem to add anything to artist critique that was not already present. It seems to me that Stiegler, on the other hand, has some fairly clear ideas about how artist critique (not under that term, of course) might be revived and rethought.

To understand how this is so let us return to Boltanski and Chiapello's polemical account of how Derrida undermines the critique of capitalism by undermining one of the most important foundations of authenticity, the priority of speech over writing in Rousseau. As we have seen, the authors of The New Spirit of Capitalism argue that Rousseau founds authenticity and founds it on a metaphysics of presence. Any attempt to deconstruct such a metaphysics thereby derails the critique of capitalist inauthenticity. But this assumes that the critique of inauthenticity requires the positive affirmation of the 'authentic' and, beyond that, metaphysics. In a sense (that is, in the very general one in which Boltanski and Chiapello use the term 'authentic') it is exactly this impasse that Stiegler's account of individuation seeks to avoid. Criticising the 'loss of individuation' in hyperindustrial capitalism does not imply, for Stiegler, the affirmation of an authentic individual, present to her or himself. Rather the process of individuation is conceived upon Derridean lines as a differing deferral of presence that is disrupted or short circuited by capitalism in its 'hyperindustrial' current form. At no point does this mean that we found either the individual or collective group (people) on the basis of a self-sufficient 'presence'. That is the major point of Stiegler's deployment of the Simondonian concept of indviduation. It is not about affirming the voice of the individual or people against the impersonal forces of technological capitalism. It is instead about the 'ecological' preservation of the process of individuation in which these are formed, one which is implicitly 
technical (and therefore also implicitly concerned with difference in Derrida's sense). Indeed one might argue that one of Stiegler's principle achievements is to see how the deconstruction of speech and writing (understood as an argument about fundamental technicity, or default of origin) could be rethought precisely as a critique of the inauthenticity of capitalism. Of course, he does not conceive it in quite those terms, being not committed to Boltanski and Chiapello's terminology and, more widely, the conceptual baggage of authenticity. But undoubtedly his arguments about disindividuation and symbolic misery do fall into their general rubric of 'artist critique', that is to say the critique of the tendency of capitalism towards homogeneity and conformity. In that sense Stiegler's project can be seen as the revival of critique that The New Spirit of Capitalism calls for.

\section{References}

Adorno, T. \& Horkheimer, M. ([1944] 1979), Dialectic of Enlightenment, London: Verso.

Adorno, T. W. ([1964] 1973), The Jargon of Authenticity, Evanston, Ill.: Northwestern University Press.

Boltanski, L. \& Chiapello, E. (2007), The New Spirit of Capitalism, Trans. G. Elliott, London: Verso.

Budgen, S. (2000), ‘A New “Spirit of Capitalism”, New Left Review: 149-156.

Chiapello, E. (2004), 'Evolution and co-optation', Third Text 18 (6): 585-594.

Gilbert, J. et al. (2010), ‘The new spirit of capitalism', Soundings 45.

Heidegger, M. ([1927] 1962), Being and Time, Trans: J. Macquarrie \& E. Robinson, Oxford: Blackwell.

Noys, B. (2010), 'Apocalypse, Tendency, Crisis', Mute: Culture and Politics after the Net 2 (15), http://www.metamute.org/editorial/articles/apocalypse-tendency-crisis.

Roberts, B. (2006), 'Cinema as mnemotechnics: Bernard Stiegler and the industrialisation of memory', Angelaki 11 (1): 55-63.

Roberts, B. (2012), 'Technics, Individuation and Tertiary Memory: Bernard Stiegler's challenge to media theory', New Formations 77: 8-20.

Simondon, G. (1958), Du Mode d'existence des objets techniques, Paris: Aubier.

Simondon, G. (2007), L'Individuation psychique et collective: à la lumière des notions de forme, information, potentiel et metastabilite, Paris: Aubier.

Sinnerbrink, R. (2009), 'Culture Industry Redux: Stiegler and Derrida on Technics and Cultural Politics', Transformations 17, http://www.transformationsjournal.org/journal/issue_17/article_05.shtml.

Stiegler, B. (2006), Mécréance et Discrédit: 3. L’Esprit perdu du capitalisme, Paris: Galilée.

Weber, M. ([1905] 1958), The Protestant Ethic and the Spirit of Capitalism. New York: Scribner. 
${ }^{1}$ Hereafter I will refer to 'artist crtique'. As Chiapello puts it 'I prefer to speak of "artist critique" rather than "artistic critique" - especially since the latter is an ambiguous term liable to mean that artists are the subject of either the critique or its target' (2004: 586).

${ }^{2}$ Of course, as Kate Nash among others has pointed out, there is a legitimate question to be asked here about how much an analysis of management literature can tell you about the actual attitudes of management cadres toward their work (Gilbert et al. 2010).

${ }^{3}$ On the tendential understanding of capitalist crisis, see (Noys 2010)

4 The use of the term Eigentlichkeit comes in the context of Being and Time's discussion of Dasein's 'ownmost possiblity'. As Macquarrie and Robinson, Heidegger's English translators, note, 'The connection between eigentlich ("authentic", "real") and eigen ("own") is lost in translation' (Heidegger 1962: 68n3). 